\title{
La Ley 10/2015 para la Salvaguarda del PCI (2013-2014): ¿patrimonio inmaterial o nacionalismo de Estado?
}

Desde el pasado mes de mayo está en vigor la nueva Ley del Patrimonio Cultural Inmaterial del Estado. Con su puesta en marcha, se autoriza al Gobierno a elaborar, en el plazo de un año, un texto refundido en el que se integren esta norma y la del Patrimonio Histórico Español, así como las disposiciones en materia de protección del patrimonio histórico contenidas en normas con rango de ley. Durante su presentación en el Congreso en diciembre del pasado año, el entonces ministro Wert defendió que con este proyecto legislativo se daba cumplimiento a la Convención de Salvaguardia del Patrimonio Inmaterial de la UNESCO, ratificada por España en 2006. Su objetivo, según señaló, es proteger patrimonio que carece de una base material pero es "importante" por la diversidad cultural, citando a las tradiciones, rituales, actos festivos, saberes y prácticas vinculadas a tradición artesanal. Esta ley ha salido adelante a pesar de las críticas, entre otras, que la acusaban de invadir competencias autonómicas.

Gema Carrera Díaz | antropóloga, Centro de Documentación del IAPH

URL de la contribución <www.iaph.es/revistaph/index.php/revistaph/article/view/3674>

El 27 de mayo de 2015 fue publicada en BOE la Ley 10/2015, de 26 de mayo, para la salvaguardia del Patrimonio Cultural Inmaterial, tras un previo anteproyecto (noviembre de 2013) y un proyecto de Ley (octubre de 2014). El texto ha ido mejorando progresivamente en las formas aunque en los contenidos se mantienen las mismas contradicciones iniciales, algunas de ellas ciertamente preocupantes.

El objeto "explícito" de esta ley es "regular la acción general de salvaguardia que deben ejercer los poderes públicos (estatales, autonómicos...) sobre los bienes que integran el patrimonio cultural inmaterial, en sus respectivos ámbitos de competencias" (art. 1).

Para ello, en su preámbulo, se realiza un gran esfuerzo conceptual y jurídico para justificar su necesidad frente a otras alternativas (como la no regulación o reformulación de la ley 16/1985): se afirma que da cumplimiento a la Convención para la Salvaguardia del Patrimonio Cultural Inmaterial de UNESCO (2003), que completa la Ley 16/1985, de 25 de junio de Patrimonio Histórico Español (LPHE) y que respeta el orden constitucional de distribución de competencias entre las CCAA y el Estado. Siendo esta última una de las mayores contradicciones que esta ley intenta superar, sin conseguirlo.
Para la protección de los bienes inmateriales de "mayor representatividad y relevancia cultural de España", se pretende crear una categoría jurídica específica denominada "Manifestación Representativa del Patrimonio Cultural Inmaterial" (en adelante MRPCI). Es decir, el Estado no solo pretende homogeneizar, no respetando la diversidad cultural, sino además pretende jerarquizar. La creación de esta figura es quizás lo más contradictorio de la ley por varios motivos.

Por un lado, supone un cambio cualitativo con relación al modelo impuesto por la sentencia constitucional 17/1991, de 31 de enero, que retiró casi por completo la atribución de efectuar declaraciones a la Administración General del Estado. Sin embargo, en el texto del proyecto de Ley se intenta invalidar esta sentencia para el caso del PCl en base a una serie de supuestos (art. 12). La ley se construye en base a una lectura errónea del calificativo "inmaterial" que se aprovecha para deslocalizar y atribuirse competencias (el calificativo inmaterial no se refiere a la intangibilidad sino a la componente procesual de este patrimonio). "Cuando superen el ámbito territorial de una Comunidad Autónoma y no exista un instrumento jurídico de cooperación entre Comunidades Autónomas para la protección integral de este bien". (art. 12. apartado 1.a). 
Por otro lado, esta ley y sus precedentes (anteproyecto y proyecto) basan su existencia en la base de un principio incoherente con la salvaguarda de este patrimonio: el de la homogeneidad frente a la diversidad cultural.

Un recuperado y renovado nacionalismo español intenta imponerse utilizando como coartada un texto jurídico internacional que, frente a estas intenciones de homogeneización, defiende precisamente la diversidad cultural y la pluralidad (la Convención de 2003).

El Estado español, a pesar de tener reconocidas 17 Comunidades Autónomas -CC.AA.- competentes en patrimonio cultural, pretende convertirse con este instrumento en el defensor de expresiones culturales inmateriales que supuestamente sobrepasan los límites de una comunidad autónoma. Algunos ejemplos citados en artículos o noticias relativos a la aprobación del anteproyecto y proyecto de ley hacen referencia al flamenco, los toros, la "cultura de la semana santa"; las fiestas de moros y cristianos... La maniobra jurídica es preocupante. Un malabarismo jurídico muy sutil y al mismo tiempo un tanto tosco pretende invalidar lo que fue un importante paso en el respeto de las identidades culturales en el Estado español (las competencias en cultura delegadas a las CC. AA.).

Por otro lado, la mayoría de las expresiones culturales que podrían incluirse en el concepto de PCI las detentan grupos o comunidades que, como afirma la propia definición de la Convención de 2003, las recrean constantemente "en función de su entorno, su interacción con la naturaleza y su historia".

No existe prácticamente ninguna expresión cultural deslocalizada, que no esté vinculada con un grupo cuyo marco territorial esté claramente definido. Normalmente, suelen desarrollarse en un ámbito territorial municipal o supramunicipal. Determinadas manifestaciones pueden extenderse y practicarse por otras comunidades o grupos o realizarse en otros territorios distintos al lugar en que se origina la práctica. Pero ésta no será nunca igual y cobrará nuevos significados y aspectos formales de acuerdo con el grupo que lo practica o celebra y el territorio con el que este interactúa.

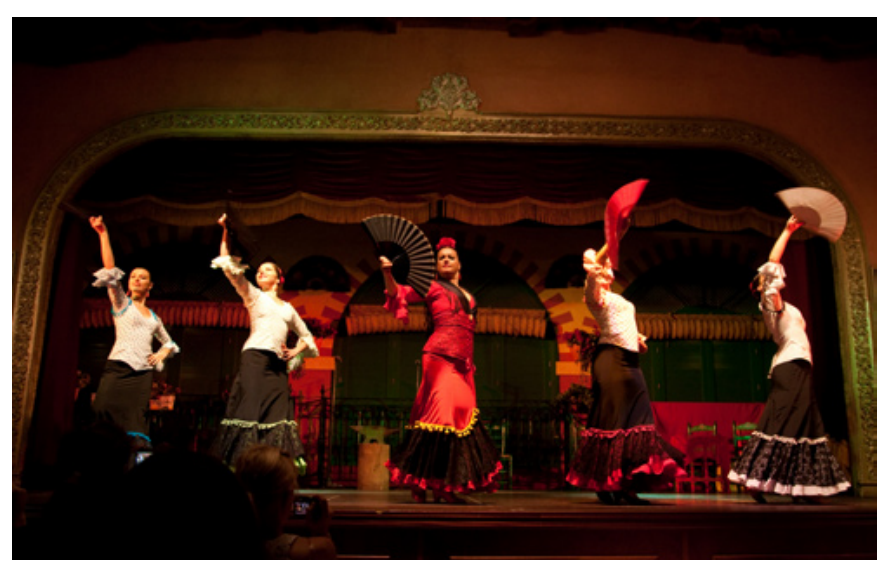

Espectáculo de flamenco para turistas en El Palacio Andaluz (Sevilla) | foto Andrés Terraza

Otra cuestión es que se puedan hacer relaciones asociativas entre prácticas con características comunes como podría hacerse con el patrimonio cultural inmueble, entre las catedrales góticas o iglesias románicas o palacios renacentistas de toda España. ¿Deslocalizaría esta asociación tipológica a los inmuebles representativos de estos estilos arquitectónicos o periodos históricos? ¿justificaría esto la posibilidad del Estado de realizar una declaración unitaria del patrimonio cultural de estilo renacentista, gótico, como ha propuesto hacer con el repentismo o con la semana santa?

En definitiva, la cuestión es que basar la ley en una prerrogativa estatal de declarar MRPCl en los casos en los que haya manifestaciones que transgredan el ámbito territorial de una comunidad autónoma resulta un argumento altamente inapropiado. Primero, porque no por ello ha de convertirse en representativa de todo un Estado. Y en segundo lugar porque las competencias autonómicas en patrimonio cultural no están reñidas con que las CC. AA. puedan asumir de forma coordinada la salvaguarda de un $\mathrm{PCl}$ siempre que su población lo considere como parte de su patrimonio cultural y convengan en practicar medidas conjuntas.

Por otro lado, si tenemos en cuenta los principios y valores de la Convención, en la que supuestamente la ley se basa, el primer valor es la primacía de las comunidades, grupos o individuos en lo relativo a la salvaguardia de su propio patrimonio cultural inmaterial "en el marco de 
sus actividades de salvaguardia del patrimonio cultural inmaterial, cada Estado Parte tratará de lograr una participación lo más amplia posible de las comunidades, los grupos y, si procede, los individuos que crean, mantienen y transmiten ese patrimonio y de asociarlos activamente a la gestión del mismo" (art. 15 de la Convención UNESCO, 2003).

Según este argumento, el Estado no debería obligar a ningún grupo a conservar una expresión cultural con la que no se siente identificado o que no desea practicar. En el mismo sentido, tampoco se debería prohibir una práctica cultural con la que un grupo se siente representado, siempre que "sea compatible con los instrumentos internacionales de derechos humanos existentes y con los imperativos de respeto mutuo entre comunidades, grupos e individuos y de desarrollo sostenible" (art. 2 de la Convención). La ley no tiene en cuenta la "previa petición de la comunidad portadora" en el caso de la declaración de un MRPCI. Sólo contempla "el trámite de audiencia a las comunidades portadoras del bien, a los titulares de derechos reales sobre los bienes muebles e inmuebles asociados a la Manifestación Representativa del Patrimonio Cultural Inmaterial, y a las Administraciones autonómicas y locales del territorio en el que la manifestación tiene lugar." (art. 12.4. b de la Ley 10/2015).

En el anteproyecto de Ley (2013) aparecía como segundo supuesto para la realización de declaraciones de MRPCI que: "el bien inmaterial a salvaguardar no pueda separarse del imaginario y tradición española en su conjunto, y no se vincule a región alguna en particular" (anteproyecto de ley en fase de consulta). Ello ha sido sustituido y matizado en la ley por "Cuando la consideración en conjunto del bien objeto de salvaguardia requiera para su específica comprensión una consideración unitaria de esa tradición compartida, más allá de la propia que pueda recibir en una o varias Comunidades Autónomas" (art. 12. apartado 1.c).

Entre las disposiciones finales, la sexta hace referencia a la regulación de la tauromaquia como patrimonio cultural (el gran bastión cultural que ha defendido el gobierno en su última legislatura ante la iniciativa cata- lana de prohibir las corridas de toros). Este constituye un indicador obvio de la instrumentalización de este patrimonio para la lucha política en la construcción de las identidades. "Lo establecido en la presente Ley se entiende, en todo caso, sin perjuicio de las previsiones contenidas en la Ley 18/2013, de 12 de noviembre, para la regulación de la Tauromaquia como patrimonio cultural" (disposición 5.ª).

No faltan alusiones a las intenciones explícitas y latentes de mercantilización de la cultura cuando se mencionan los principios generales de las actuaciones de salvaguarda. Parece que de todo puede "protegerse" el PCI menos del mercado: "Las actuaciones que se adopten para salvaguardar los bienes jurídicos protegidos deberán, en todo caso, respetar los principios de garantía de la libertad de establecimiento y la libertad de circulación establecidos en la normativa vigente en materia de unidad de mercado" (art. 3. j.).

Se hace también alusión a las medidas indirectas de salvaguarda mediante la protección de elementos materiales (muebles o inmuebles) (art. 4.) Con ello, de manera igualmente indirecta, el Estado se otorga competencias sobre los bienes muebles e inmuebles localizados en los territorios de las CC. AA. y además le permite poder introducir un artículo sobre "Expoliación y Exportación de bienes muebles", única competencia que tiene el Estado en materia de patrimonio cultural (art. 5).

Por último, el texto de la Convención de 2003, que esta ley pone como referente, es un alegato a favor de la diversidad cultural, siendo esta diversidad y su interés por salvaguardarla lo que constituye un patrimonio de la humanidad. Sin embargo, esta ley, desde mi punto de vista, defiende una imagen homogénea del Estado español y una forma de concebir la gestión del patrimonio completamente alejada de criterios y principios de participación social impulsadas desde abajo hacia arriba y no al contrario, como es el caso. 